\title{
Mass Spectra of the Tetramethyl Compounds of Carbon Silicon, Germanium, Tin, and Lead ${ }^{1}$
}

\author{
Vernon H. Dibeler
}

\begin{abstract}
Mass spectra of $\mathrm{C}\left(\mathrm{CH}_{3}\right)_{4}, \mathrm{Si}\left(\mathrm{CH}_{3}\right)_{4}, \mathrm{Ge}\left(\mathrm{CH}_{3}\right)_{4}, \mathrm{Sn}\left(\mathrm{CH}_{3}\right)_{4}$, and $\mathrm{Pb}\left(\mathrm{CH}_{3}\right)_{4}$ were obtained with a Consolidated 21-103 mass spectrometer. Isotopic abundances of carbon, silicon, germanium, tin, and lead were obtained from the observed spectra and used to calculate the monoisotopic spectra. The mass spectra of the Group IV tetramethyls are qualitatively similar. The principal ion in each case results from the dissociation of one methyl group. The molecule ion and ions resulting from the dissociation of hydrogen atoms are rare. Hydrides of the atom ions and the mono-, di-, and tri-methyl ions were observed. Some evidence is pointed out for the possible formation of the $\mathrm{CH}_{3}+$ ion and the $\mathrm{C}_{2} \mathrm{H}_{5}+$ ion in neopentane as hydrides of the central carbon atom.
\end{abstract}

\section{Introduction}

A previous paper $[1]^{2}$ reported the mass spectra of several organolead and organomercury compounds. A brief discussion was given of the dissociation processes in the mass spectrometer and of the applicability of these molecules to the isotopic analysis of the metallic elements. The results of a similar study of the Group IV tetramethyl compounds are reported here.

Although the mass spectra of both neopentane and lead tetramethyl have been reported previously [1, 2], significant instrumental modifications have since been made, so that these spectra were remeasured to simplify direct comparison with the other compounds.

The isotopic abundance of germanium, tin, and lead were first measured by Aston [3] by using the alkyl compounds of these elements. Because of hydride formation during the ionization and dissociation processes, recent measurements have been made on inorganic halide compounds of these elements. The low vapor pressure of the tin and lead halides, however, introduces experimental difficulties not encountered when using the metal alkyls. Furthermore, this research and others recently reported $[1,4]$ indicate that, in spite of the necessary corrections to the spectra for ions resulting from dissociation processes and hydride formation, isotopic abundances of the metals can be measured with a precision comparable to that obtained from measurements on inorganic halides.

\section{Experimental Details}

Mass spectra were obtained with a Consolidated 21-103 mass spectrometer. The energy of the ionizing electrons was nominally 70 volts and the temperature of the ion source was $250^{\circ} \mathrm{C}$. The metastable suppressor, which also acts as a virtual slit at the collector end of the analysor, was adjusted to give a resolution of about 1 in 300 . Routine techniques and procedures were used to obtain all the data.

Liquid samples were introduced into the reservoir through a glass frit covered with liquid gallium.

\footnotetext{
1 Presented at the Pittsburgh Conference on Analytical Chemistry and Applied Spectroscopy, March 1952

2 Figures in brackets refer to references at the end of the paper.
}

Neopentane and silicon tetramethyl were introduced by evaporation from liquid stored in glass ampoules with internal break seals. The pressure of the samples in the reservoir was measured with a micromanometer [5].

The neopentane was National Bureau of Standards Standard Sample 299, with a stated purity of 99.96 \pm 0.02 mole percent.

Silicon tetramethyl was kindly supplied by the General Electric Research Laboratory. A trace of methyl bromide was the only impurity of the material observed in the mass spectrum.

Germanium tetramethyl was prepared from methyl magnesium bromide and germanium tetrachloride in dibutyl ether. The final product, obtained in low vield, contained only a few tenths of a mole percent impurities, principally butyl ether. A second preparation from zine dimethyl and germanium tetrachloride [6] gave nearly quantitative yields of high-purity product.

Tin tetramethyl was kindly supplied by the Metal and Thermit Corporation, New York. Total impurities, principally toluene, diethyl ether, and benzene, were estimated to be less than 2 mole percent.

Lead tetramethyl, obtained from the Ethyl Corporation, was the same sample as that previously described [1].

\section{Results}

In order to compare the relative probabilities of the various dissociation processes in these molecules, it is first necessary to calculate the spectra that would be obtained if all the constituent elements were monoisotopic (that is, the monoisotopic spectrum). For this purpose the isotopic abundances of the elements, except hydrogen, are best calculated from the observed spectra. These values, calculated as described below and summarized in table 2, are compared with previously reported values.

Table 1 presents in brief form portions of the polyisotopic spectra ${ }^{3}$ of the tetramethyl compounds to illustrate the calculations of the isotopic abundances and of the monoisotopic spectra. Excepting the

3 The detailed polyisotopic spectra of neopentane and lead tetramethyl have been published, and theispectra of the silicon, germanium, and tin compounds will be submitted for publication in reference [2] 
spectrum of neopentane, the contributions of ions containing $\mathrm{C}^{13}$ and $\mathrm{D}$ atoms have been subtracted as described below. Thus the organometallic compounds are polyisotopic with respect to the central metallic atom only. The relative ion abundances are given in the conventional way, that is, relative to the most abundant ion.

It is possible to calculate the $\mathrm{C}^{12} / \mathrm{C}^{13}$ abundance ratio in neopentane from the ion abundances in the $\mathrm{C}_{4}$ group by assuming a value for the abundance of deuterium. Except for a negligible correction, all of the 55 peak (column 1, table 1 ) is attributed to the

TABle 1. Partial polyisotopic spectra of the Group IV tetramethyl compounds for 70 -v electrons

\begin{tabular}{|c|c|c|c|c|c|c|c|c|c|}
\hline$m / e$ & $\mathrm{C}\left(\mathrm{CH}_{3}\right)_{4}$ & $m / e$ & $\mathrm{Si}\left(\mathrm{CH}_{3}\right)_{4}$ & $m / e$ & $\mathrm{Ge}\left(\mathrm{CH}_{3}\right)_{4}$ & $m / e$ & $\mathrm{Sn}\left(\mathrm{CH}_{3}\right)_{4}$ & $m / e$ & $\mathrm{~Pb}\left(\mathrm{CH}_{3}\right)_{+}$ \\
\hline 27 & 16.98 & 28 & 3.52 & 70 & 4. 37 & 112 & 0.61 & 204 & 1.82 \\
\hline 28 & 2.85 & 29 & 7.91 & 71 & 6.43 & 113 & .33 & 205 & 0.17 \\
\hline 29 & 35.77 & 30 & 0.78 & 72 & 5. 83 & 114 & .42 & 206 & 36.78 \\
\hline \multirow[t]{2}{*}{30} & 0.82 & 31 & 3. 71 & 73 & 10.34 & 115 & .45 & 207 & 31.70 \\
\hline & & & & 74 & 10.06 & 116 & 9.08 & 208 & 73.65 \\
\hline 41 & 43. 78 & 42 & 4. 20 & 75 & 11. 56 & 117 & 9. 76 & 209 & 6. 62 \\
\hline 42 & 3.18 & 43 & 15. 98 & 76 & 1. 77 & 118 & 17. 56 & & \\
\hline 43 & 1. 60 & 44 & 3.82 & 77 & 2. 80 & 119 & 13. 61 & 217 & 0.07 \\
\hline \multirow[t]{2}{*}{44} & 0.52 & 45 & 12.55 & & & 120 & 23.07 & 218 & .64 \\
\hline & & 46 & 0.69 & 85 & 13. 67 & 121 & 11. 21 & 219 & 4. 29 \\
\hline 54 & 23 & 47 & .41 & 86 & 4. 28 & 122 & 2. 95 & 220 & 5. 70 \\
\hline 55 & 3.06 & & & 87 & 21.86 & 123 & 1. 60 & 221 & 53.00 \\
\hline 56 & 3. 80 & 58 & 2. 06 & 88 & 9. 94 & 124 & 3. 59 & 222 & 43. 26 \\
\hline 57 & 100.0 & 59 & 2. 42 & 89 & 26. 39 & 125 & 2. 06 & 223 & 90.84 \\
\hline \multirow[t]{2}{*}{58} & 4. 53 & 60 & 0.17 & 90 & 2. 54 & & & 224 & 0.90 \\
\hline & & & & 91 & 9. 91 & 157 & 3.01 & & \\
\hline \multirow{11}{*}{72} & 0.02 & 71 & .42 & 92 & 0.10 & 158 & 0.02 & 249 & 2. 56 \\
\hline & .01 & $\begin{array}{l}72 \\
73\end{array}$ & $\begin{array}{r}.92 \\
1000\end{array}$ & 114 & 33 & 159 & $\begin{array}{l}2.06 \\
1.43\end{array}$ & $\begin{array}{l}250 \\
251\end{array}$ & $\begin{array}{r}0.49 \\
52.44\end{array}$ \\
\hline & & 74 & 4. 97 & 115 & 56.64 & 161 & 45.03 & 252 & 41. 11 \\
\hline & & 75 & 3. 25 & 116 & 0.45 & 162 & 24.18 & 253 & 100.0 \\
\hline & & & & 117 & 75.61 & 163 & 74. 71 & 254 & 1.00 \\
\hline & & 88 & 0.77 & 118 & $\begin{array}{r}21.82 \\
1\end{array}$ & 164 & 27.45 & & \\
\hline & & 89 & .04 & 119 & 100.0 & 165 & 100.0 & 266 & 0.11 \\
\hline & & 90 & .03 & 120 & 0.17 & 166 & 0.32 & 267 & .08 \\
\hline & & & & 121 & 21.15 & $\begin{array}{l}167 \\
168\end{array}$ & 14. 29 & 268 & .22 \\
\hline & & & & 134 & 0.41 & 169 & 17. 77 & & \\
\hline & & & & & & 170 & 0.07 & & \\
\hline
\end{tabular}

$\mathrm{C}_{4}^{12} \mathrm{H}_{7}{ }^{+}$ion. A sufficiently accurate calculation of the contribution of the $\mathrm{C}^{13} \mathrm{C}_{3}^{12} \mathrm{H}_{7}{ }^{+}$ion to the 56 peak is obtained by multiplying the abundance of the 55 peak (3.06) by an approximate value for the $\mathrm{C}^{13}$ abundance times the number of carbon atoms, $(3.06)(0.01)(4)=0.12$. This contribution is subtracted from the 56 peak (3.80) to give the abundance of the $\mathrm{C}_{4}^{12} \mathrm{H}_{8}{ }^{+}$ion (3.68). Similarly, the correction to the 57 peak for the $\mathrm{C}^{13} \mathrm{C}_{3}^{12} \mathrm{H}_{8}{ }^{+}$ion is given by $(3.68)(0.01)(4)=0.15$, and the corrected abundance of the $\mathrm{C}_{4}^{12} \mathrm{H}_{9}{ }^{+}$ion is $100-0.15=99.85$. Next, the small but measurable contribution of the $\mathrm{C}_{4}^{12} \mathrm{H}_{8} \mathrm{D}^{+}$ ion to the 58 peak is calculated by assuming an $\mathrm{H} / \mathrm{D}$ ratio of 6700 [7]. This corresponds to a deuterium abundance of 0.0149 atom percent. Thus the contribution $(99.85)(0.000149)(9)=0.13$ is subtracted from the 58 peak (4.53) to give the abundance of the $\mathrm{C}^{13} \mathrm{C}_{3}^{12} \mathrm{H}_{9}{ }^{+}$ion (4.40). The observed $\mathrm{C}^{13}$ abundance is therefore 1.10 percent of the $\mathrm{C}^{12}$ abundance. This corresponds to $1.08_{8}$ atom percent $\mathrm{C}^{13}$.

$\mathrm{By}$ using the observed $\mathrm{C}^{13}$ abundance and the deuterium abundance given above, the monoisotopic spectrum of neopentane has been obtained (column 2 , table 3) by subtracting from the polyisotopic spectrum the separate contributions of ions containing $\mathrm{C}^{12}$ and $\mathrm{D}$ atoms and ions containing $\mathrm{C}^{13}$ and $\mathrm{H}$ atoms. It can be shown that contributions of ions containing more than one $\mathrm{C}^{13}$ atom or ions containing $\mathrm{C}^{13}$ and $\mathrm{D}$ atoms have a negligible effect on these calculations. The organometallic spectra given in table 1 were similarly corrected for contributions of ions containing $\mathrm{C}^{13}$ and $\mathrm{D}$ atoms. However, the monoisotopic spectra with respect to the metal ions were calculated in the more precise way previously illustrated in detail for lead [1].

TABLE 2.-Summary of isotopic abundances used in computing the monoisotopic spectra of the Group IV tetramethyl compounds

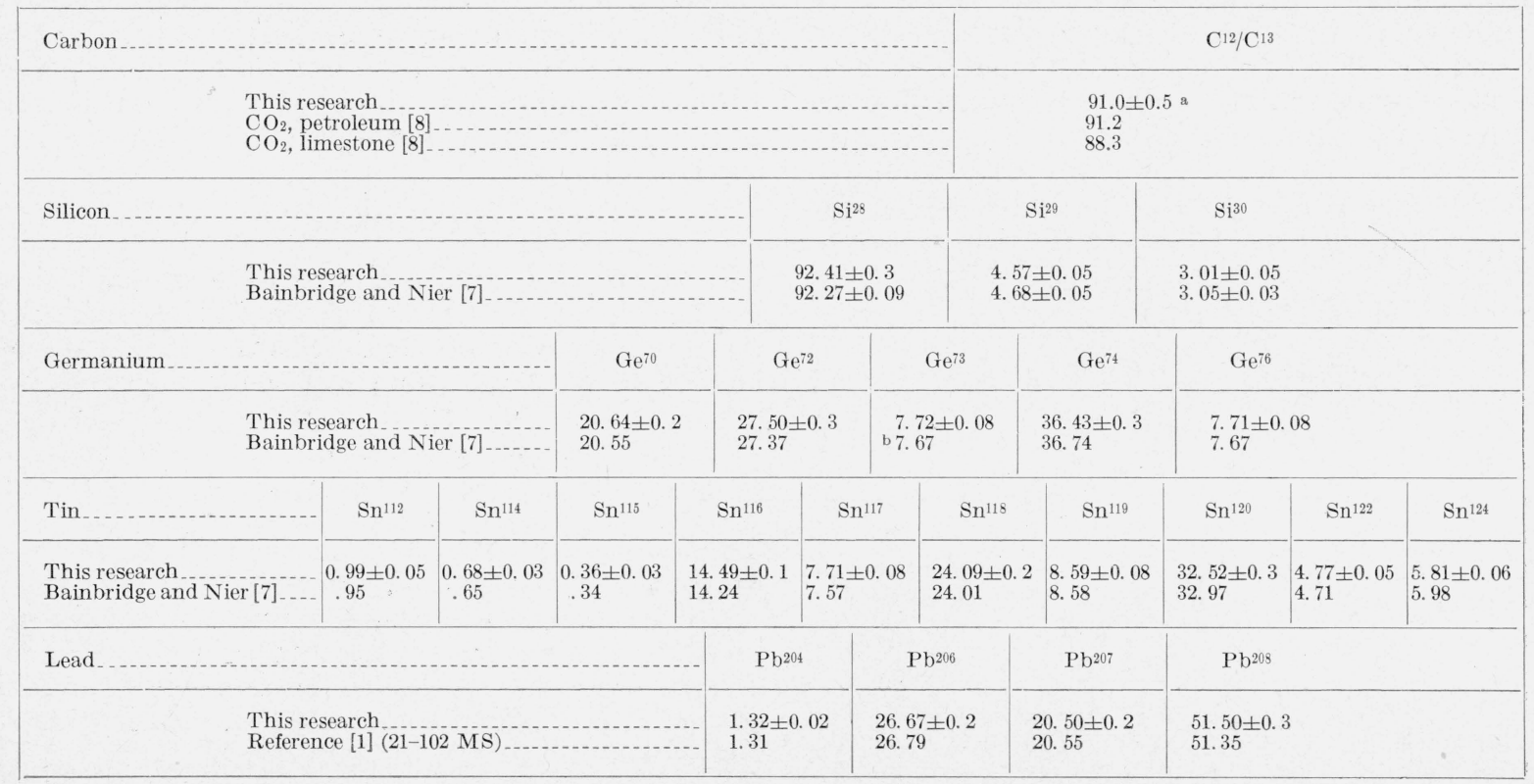

a Estimated limit to instrumental errors possibly present.

b The value of $7.61 \%$ for $\mathrm{Ge}^{73}$ given in [7] is the result of a misprint in the original reference, as noted by Graham, et al. [12]. 
The partial spectrum of silicon tetramethyl is given in column 2 , table 1 . As in the carbon compound, the trimethyl ions $(m / e=73,74$, and 75$)$ are the most suitable for calculating the isotopic abundance of silicon. As no 76 peak was observed, the absence of a monohydride of the trimethyl ion is assumed. The ratio $\mathrm{Si}\left(\mathrm{CH}_{3}\right)_{3} \mathrm{H}^{+} / \mathrm{Si}\left(\mathrm{CH}_{3}\right)^{+}{ }_{3}$ is estimated to be less than 0.002 . However, the presence of ions $m / e=71$ and 72 , indicates the necessity of making corrections for contributions of ions resulting from the dissociation of hydrogen atoms. To a good approximation, the abundances of the ions $\mathrm{Si}\left(\mathrm{CH}_{3}\right)_{2} \mathrm{CH}^{+}$and $\mathrm{Si}\left(\mathrm{CH}_{3}\right)_{2} \mathrm{CH}_{2}{ }^{+}$relative to $\mathrm{Si}\left(\mathrm{CH}_{3}\right)_{3}{ }^{+}$ are given by the ratio of the peaks $71: 72: 73=$ $0.0042: 0.0092: 1.00$. As the 75 peak is attributed to $\mathrm{Si}^{30}\left(\mathrm{CH}_{3}\right)_{3}{ }^{+}$only, multiplying its abundance (3.25) by the above ratios gives the contributions of the $\mathrm{Si}^{30}\left(\mathrm{CH}_{3}\right)_{2} \mathrm{CH}_{2}{ }^{+}(0.03)$ and the $\mathrm{Si}^{30}\left(\mathrm{CH}_{3}\right)_{2} \mathrm{CH}^{+}$(0.01) ions to the 74 and 73 peaks, respectively. Subtracting the 0.03 from the 74 peak (4.97) gives the corrected $\mathrm{Si}^{29}\left(\mathrm{CH}_{3}\right)_{3}{ }^{+}$ion contribution. Multiplying this by the above ratios gives the ions containing $\mathrm{Si}^{29}$ and permits calculation of the corrected $\mathrm{Si}^{28}\left(\mathrm{CH}_{3}\right)_{3}{ }^{+}$ion. The isotopic abundance of silicon calculated from the trimethyl ions appears in table 2 . The monoisotopic spectrum calculated therefrom appears in column 3 , table 3 .

The partial polyisotopic spectrum of germanium tetramethyl is given in column 3, table 1. Again, the isotopic abundance is calculated from the

TARLE 3.-Monoisotopic spectra of the tetramethyl compounds of carbon, silicon, germanium, tin, and lead for $70-v$ electrons

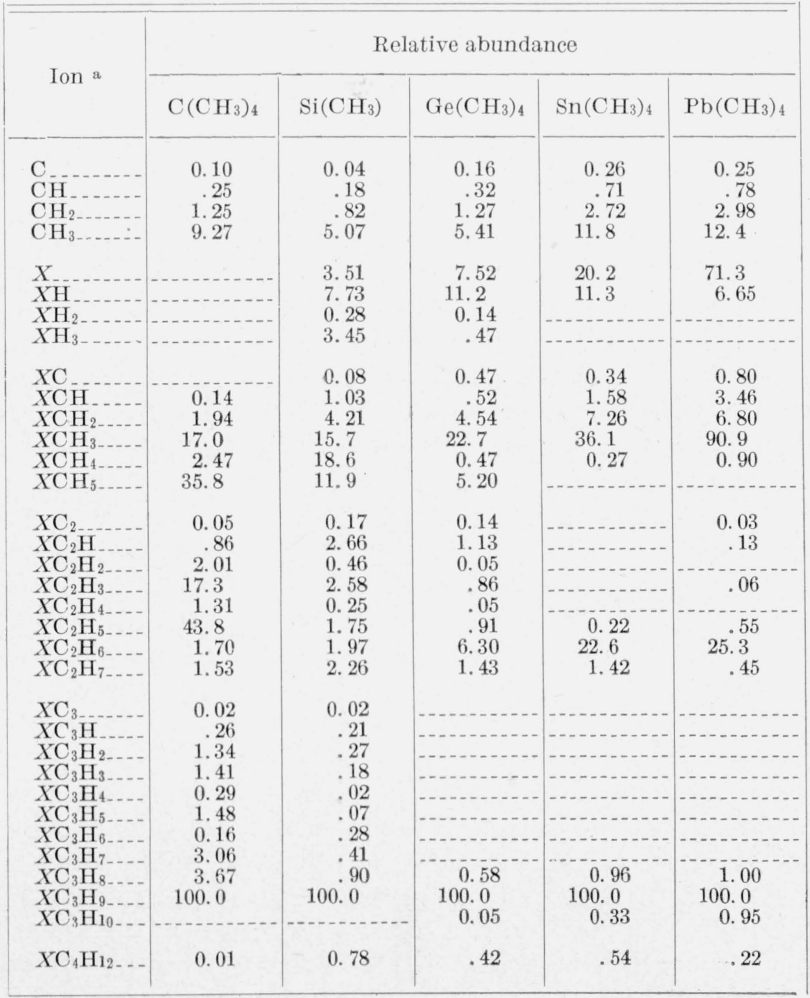

- $X$ represents the central atom of each of the five compounds. trimethyl ions $(m / e=115$ to 121$)$. As no $m / e 221=$ was observed, the absence of a monohydride of the trimethyl ion was assumed. The ratio $\mathrm{Ge}\left(\mathrm{CH}_{3}\right)_{3^{-}}$ $\mathrm{H}^{+} / \mathrm{Ge}\left(\mathrm{CH}_{3}\right)_{3}{ }^{+}$was estimated less than 0.001 . The presence of a 114 peak, however, indicated the dissociation of one hydrogen atom with an approximate abundance ratio $\mathrm{Ge}\left(\mathrm{CH}_{3}\right)_{2} \mathrm{CH}_{2}{ }^{+} / \mathrm{Ge}\left(\mathrm{CH}_{3}\right)_{3}=$ 0.0058. Using this value the contributions of the isotopic ions of $\mathrm{Ge}\left(\mathrm{CH}_{3}\right)_{3}{ }^{+}$and of $\mathrm{Ge}\left(\mathrm{CH}_{3}\right)_{2} \mathrm{CH}_{2}{ }^{+}$ were obtained. However, a small residual remained on the $m / e=120$ peak corresponding to a monohydride ratio of $\mathrm{Ge}\left(\mathrm{CH}_{3}\right)_{3} \mathrm{H}^{+} / \mathrm{Ge}\left(\mathrm{CH}_{3}\right)^{+}{ }_{3}=0.0005$. 'This small correction was included, and the isotopic abundance was calculated as described for silicon. The observed values are given in table 2. The monoisotopic spectrum appears in column 4, table 3.

The partial spectrum of tin tetramethyl is given in column 4, table 1. Because of the large number of isotopes and the possibility of overlapping of ions containing different numbers of carbon atoms, the abundances of the tin isotopes were calculated from the $\mathrm{Sn}^{+}$ions at $m / e=112$ to 124 . This results in some loss in precision. A first approximation of the $\mathrm{SnH}^{+} / \mathrm{Sn}^{+}$ratio is given by the ratio of peaks $125 / 124$. Starting from $m / e=116$ the corrected abundances of $\mathrm{Sn}^{117}, \mathrm{Sn}^{118}, \mathrm{Sn}^{119}$, and $\mathrm{Sn}^{120}$ are calculated. Then the ratio $121 / 120=0.561$ gives the more nearly correct value for the relative abundance of the monohydride ion. There are four points at which to compare the computed with the observed values. At $m / e=113$, the computed and observed abundances of $\mathrm{Sn}^{112} \mathrm{H}^{+}$are 0.34 and 0.33 , respectively. At $m / e=121$, the computed and observed values of $\mathrm{Sn}^{120} \mathrm{H}^{+}$are 11.20 and 11.21 , respectively. At $m / e=123$, the $\mathrm{Sn}^{122} \mathrm{H}^{+}$values are 1.64 and 1.60 , and at $m / e=125$, the $\mathrm{Sn}^{124} \mathrm{H}^{+}$values are 2.00 and 2.06 . The agreement between computed and observed abundances is considered good, as errors are cumulative. The isotopic abundance of the tin isotopes are given in table 2 , and the monoisotopic spectrum is summarized in column 5 , table 3.

Portions of the polyisotopic spectrum of lead tetramethyl are given in column 5, table 1 . The method of calculating the isotopic abundance from the $\mathrm{Pb}^{+}$ ions and the derivation of the monoisotopic spectrum have been described [1]. The isotopic abundances given in table 2 are not compared with values reported by other workers because of the well-known variation of abundance with origin of the sample. The source of the lead used in the present sample is not known.

\section{Discussion}

\subsection{Measurements of Isotopic Abundance}

The uncertainties indicated in table 2 are estimated errors probably present in the recording system only. For the principal isotopes, the reproducibility was at least a factor of 10 better than the estimated error. The purpose of comparing the present results with previously reported values is merely to show the extent of agreement of values obtained by using organometallic compounds and routine operating 
procedures with values obtained in other laboratories by using inorganic compounds and specialized techniques.

Nier and Gulbransen [8] and Murphey and Nier [9] have demonstrated the variation in the natural abundance of $\mathrm{C}^{13}$ with the source of material. Apparently $\mathrm{C}^{13}$ is concentrated in limestone, whereas $\mathrm{C}^{12}$ is concentrated in plant material. Although the exact origin of the neopentane sample is not known, it very probably contained carbon from petroleum sources only. The observed value of the $\mathrm{C}^{12} / \mathrm{C}^{13}$ ratio is consistent with this probability. The ratio is also consistent with values obtained from a variety of hydrocarbons, most of them certainly from petroleum sources, measured routinely in the Bureau's Mass Spectrometry Laboratory over a period of several years.

The isotopic abundances of silicon, germanium, and tin are in good agreement with the values for these elements adopted by Bainbridge and Nier [7]. This is particularly interesting in view of the possible complexity of the dissociation processes of the organometallic compounds compared with the inorganic molecules usually measured. In the case of the organometallics, it is apparently possible to make the corrections for the contributions of ions containing $\mathrm{C}^{13}$ and $\mathrm{D}$ atoms, of hydride ions, and of ions resulting from the dissociation of $\mathrm{H}$ atoms with a precision comparable with the uncertainty in recording the mass spectra. Furthermore, routine operating procedures and techniques devised for standard gas analysis apparently provide a degree of reproducibility and accuracy comparable with that of previously published results.

The present value for the isotopic abundance of lead is a remeasurement of the same sample previously measured [1] with a Consolidated 21-102 instrument. Although major modifications were made to the ion source and ion collector in the interval between the two series of measurements, the values agree within the estimated error. Because of the well-known variation in the isotopic abundance of lead, it is not very instructive to compare observed values of a sample of unknown origin with previously reported data. The present results, probably for lead of mixed origins, are within the range of isotopic abundances reported by Nier and coworkers [10] for lead from various ores.

Some advantages of using lead alkyls rather than inorganic lead halides for isotopic abundance measurements have been discussed $[1,4]$. For example, no appreciable background of lead tetramethyl remains in the ion source and analyzer tube after a very few minutes of pumping. Furthermore, in the sample-handling system used in this work less than 0.1 percent of the original sample remains in the reservoir or on the walls after five minutes of evacuation. Isolating the reservoir from the pumps at this point causes no appreciable increase in background in one-half hour. This would seem to indicate that by exercising reasonable caution, memory effects are considerably less of a problem in the case of the lead tetramethyl than in the case of lead halides. Also, the deposition of metallic lead on insulators and other parts of the ion source is not an important factor in the case of lead alkyls. The introduction of lead tetramethyl for several hours of operation produces no noticeable effects on the operation of the ion source.

Unfortunately, the formation of hydrides rules out the use of organometallic compounds in a search for rare isotopes. Also, precise correction for hydride contributions depends on previous knowledge of the absence of an isotope with a mass number equal to that of the hydride of a relatively abundant isotope.

\subsection{Dissociation Processes}

The mass spectra of the five compounds are qualitatively similar. The very low relative abundance of the molecule ion and the maximum abundance of the trimethyl ion are characteristic of molecules exhibiting this type of symmetry. The abundances of ions resulting from the dissociation of two, three, and four methyl groups increase in fairly regular fashion with increasing atomic number of the central atom. This is particularly apparent in the abundances of the ions $\mathrm{C}^{+}<\mathrm{Si}^{+}<\mathrm{Ge}^{+}<\mathrm{Sn}^{+}<\mathrm{Pb}^{+}$. The decreasing resemblance to the hydrocarbon spectrum is also apparent with increasing atomic number. The spectra of tin and lead tetramethyl are simpler than those of silicon and germanium, containing fewer hydride ions and ions resulting from the dissociation of hydrogen atoms.

Monohydrides of the metal atoms were observed in all of the organometallies. In addition, di- and trihydrides of the silicon and germanium atom ions were observed. The abundance of the trihydride ions increases from zero for tin and lead to 3.45 for $\mathrm{SiH}_{3}^{+}$, whereas the abundance of the methyl ion decreases from 12.4 in lead tetramethyl to 5.07 in silicon tetramethyl. The abundance of the $\mathrm{CH}_{3}^{+}$ ion in neopentane (9.27) indicates that some of the methyl ions in this compound may originate as trihydrides of the central carbon atom. Hydrides of the monomethyl ions were also observed in the organometallic compounds. The abundances of the dihydrides, $\mathrm{XCH}_{5}^{+}$, in carbon, silicon, and germanium (like the $\mathrm{XCH}_{3}^{+}$ions) decrease with increasing atomic number of the central atom. In the metal alkyls, these ions can only be accounted for by rearrangement of hydrogen atoms. The abundance of the $\mathrm{C}_{2} \mathrm{H}_{5}^{+}$ion in neopentane (35.8) compared with $\mathrm{Si}\left(\mathrm{CH}_{3}\right) \mathrm{H}_{2}^{+}$(11.9) and $\mathrm{Ge}\left(\mathrm{CH}_{3}\right) \mathrm{H}_{2}^{+}(5.20)$ and zero for the corresponding tin and lead ions again indicates that at least part of the $\mathrm{C}_{2} \mathrm{H}_{5}^{+}$results from the rearrangement of hydrogen atoms. This is in disagreement with the experimental evidence reported by Langer and Johnson [11] indicating that rearrangement of methyl groups is the source of these ions. Rearrangements of methyl radicals to give hydrocarbon ions containing two carbon atoms were observed in all of the metal alkyl spectra except silicon tetramethyl, in which $\mathrm{Si}^{+}$ions partially interferred. In each case, however, the most abundant of these ions $(m / e=27)$ was less than 1 percent of the trimethyl ion and their relative abundances showed no 
relation to the ethane spectrum or to the analogous ions in neopentane.

Unlike the monomethyl hydrides, the abundance of the dimethyl hydrides, $X\left(\mathrm{CH}_{3}\right)_{2} \mathrm{H}^{+}$, is a maximum for $\mathrm{Si}\left(\mathrm{CH}_{3}\right)_{2} \mathrm{H}^{+}$. Furthermore, the abundance of the trimethyl hydrides, $X\left(\mathrm{CH}_{3}\right)_{3} \mathrm{H}^{+}$, increase with increasing atomic number of the central atom. The complicated manner in which the abundance of hydride ions varies may depend on steric effects of the several methyl groups surrounding the central atom.

Except for the rare tetramethyl ions and the monohydride of the trimethyl ions of germanium, tin, and lead, a maximum number of three atoms and/or methyl groups attached to the central atom is the general rule. This would suggest that ionization occurs by the loss of a bonding electron between the central atom and a methyl group.

The author gratefully acknowledges helpful discussions and continual encouragement given by Dr. Fred L. Mohler throughout the course of this work.

\section{References}

[1] V. H. Dibeler and F. L. Mohler, J. Research NBS 47, 337 (1951) RP2259.

[2] API tables of mass spectral data, Carnegie Institute of Technology, Pittsburgh, Pa.

[3] F. W. Aston, Mass spectra and isotopes, 2d ed. (Longmans, Green \& Co., New York, N. Y., 1941).

[4] C. B. Collins, J. R. Freeman, and J. T. Wilson, Phys. Rev. 82, 966 (1951).

[5] V. H. Dibeler and F. Cordero, J. Research NBS 46, 1 (1951) RP2167.

[6] J. H. Lengel and V. H. Dibeler, J. Am. Chem. Soc. 74 , $2683(1952)$

[7] K. T. Bainbridge and A. O. Nier, Relative isotopic abundances of the elements, Preliminary Report No. 9, National Research Council, Washington, D. C.

[8] A. O. Nier and E. A. Gulbransen, J. Am. Chem. Soc., 61, 697 (1939).

[9] B. F. Murphey and A. O. Nier, Phys. Rev. 59, 771 (1941).

[10[ A. O. Nier, R. W. Thompson, and B. F. Murphey, Phys. Rev. 60, 112 (1941).

[11] A. Langer and P. Johnson, Symposium on the use of isotopes in petroleum chemistry, Chicago Meeting of the American Chemical Society, 1950.

[12] R. P. Graham, J. Macnamara, I, H. Crocker, and R. B. MacFarlane, Canadian J. Chem. 29 ,90 (1951).

Washington, June 19, 1952. 